\title{
Designing durable and flexible superhydrophobic coatings and its application in oil purification
}

\author{
Nan Wang, ${ }^{\dagger}$ Yao Lu, ${ }^{\star}$ Dangsheng Xiong, ${ }^{\star}{ }^{\dagger}$ Claire J. Carmalt, ${ }^{\ddagger}$ and Ivan P. Parkin $*$ \\ $\uparrow$ School of Materials Science and Engineering, Nanjing University of Science and Technology, \\ Nanjing 210094, China \\ \$ Department of Chemistry, University College London, WC1H 0AJ, UK \\ Email: xiongds@njust.edu.cn
}

\begin{abstract}
Lotus-inspired superhydrophobic coatings are usually mechanically weak and lack durability, this hinders their practical applications. A suspension that can be treated on various materials in any size and shape to form a mechanically durable superhydrophobic coating is developed, which retains water repellent properties after multiple cycles of abrasion, blade scratching, tape-peeling, repeated deformation, a series of environmental tests and recycling. Based on its superhydrophobicity under oil, two highly efficient systems were developed for oil purification - stirring and inverted cone systems. Small water drops converge on the coated surface that was immersed in oil through velocity-controlled stirring, or designing an inverted cone superhydrophobic surface under oil to collect water drops spontaneously. This coating can be readily used for practical applications to make a durable superhydrophobic coating that functions either in air or oils.
\end{abstract}

Keywords: superhydrophobic; mechanically durable; recycling; oil purification 


\section{Introduction}

Superhydrophobic surfaces that exhibit extreme water-repellent properties are both of scientific and industrial interest, due to their use in a range of applications, such as in water/oil separation, ${ }^{1-3}$ anti-icing, ${ }^{4-6}$ self-cleaning, ${ }^{7,8}$ drug release, ${ }^{9,10}$ and drag reduction in fluids. ${ }^{11-13}$ Inspired by Lotus leaves,${ }^{14,15}$ Salvinia, ${ }^{16}$ seaweed ${ }^{17}$ and other species in nature, ${ }^{18-22}$ a variety of man-made approaches have been pursued to mimic those surfaces to create artificial superhydrophobic surfaces. Nowadays, the mechanical, chemical and environmental stabilities of superhydrophobic surfaces have been more focused, ${ }^{23}$ in order to employ such surfaces in practical applications. However, the main drawback, which greatly hinders their application is the low robustness of superhydrophobic surfaces. Generally, water repellent properties are highly dependent on the surface micro/nanoscale morphologies, which are mechanically weak and readily abraded, leading to a loss of water repellency. ${ }^{24,25}$ In practical environments, especially when a surface is used in the open air, long term exposure to UV, high air humidity and large temperature differences, must be taken into consideration when considering the stability of the surface. Durable superhydrophobic coatings have been reported recently, ${ }^{26}$ such as acrylic polyurethane based coating, ${ }^{27}$ textured surface obtained by chemical etching, ${ }^{28,29}$ surfaces template from innately microstructured hydrogel matrix,${ }^{30}$ block-copolymer-based thin-film patterning, ${ }^{31}$ combination of rodlike palygorskite and organosilanes via spray-coating, ${ }^{32}$ fluorine-free polysiloxane/multiwalled carbon nanotubes, ${ }^{33}$ titanium dioxide materials with special wettability, ${ }^{34}$ or various coatings fabricated on fabrics/sponges/cotton. ${ }^{35-40}$ However, most of the reported surfaces are not durable enough, as they can only resist abrasion against wipes, ${ }^{28}$ fine sandpaper (e.g., 800, 1000, 2000 grid), mild droplets/sand impinging, ${ }^{30,31}$ or were easily disabled after a short distance (i.e., less than $5 \mathrm{~m}$ ) of abrasion. ${ }^{27,29,41-43}$ Besides, the mechanical stability may be simply due to the fact that the coating 
thickness is too thick to be worn out completely to expose the substrate surface underneath the superhydrophobic coating. The relationship between the wear resistance and thickness of the coating has not been fully studied. Fabric exhibits relatively better wear-resistance abilities, due to their inherent flexibility and ability to reduce direct friction between the coating and the surface. ${ }^{44}$ We created a superhydrophobic coating on a hard substrate that could resist abrasion on 200 grid sandpaper (loading pressure $=2.25 \mathrm{kPa}$ ) for over $965 \mathrm{~cm}$ with small wear loss/thickness, suggesting superior mechanical stability than reported work.

In some of the current preparative techniques (e.g. spin coating, CVD etc.), it is very difficult to make uniform and durable superhydrophobic coatings on a shaped substrate, such as the inside of a metal tube or cube. One possibility is to fabricate the superhydrophobic coatings on a flat substrate and then bend or deform the treated substrate into a shape. However, the coatings would then be subject to the stress and strain resulting from the deformation during shaping, and a break down and loss of water repellent properties is extremely likely. To meet industrial demands, a superhydrophobic coating should possess not only mechanical stability, but also superior resilience so as to tolerate the bending or deforming, to enable its fabrication not to be limited by the size or shape of a given substrate. For the aforementioned reasons, improved mechanical durability are the main concerns of research into superhydrophobic surfaces. However, there would also be some environmental problems if superhydrophobic coatings are abandoned after their applications because they usually contain the nanomaterials with low surface energy, e.g. perfluorinated acid. $^{45-47}$ Therefore, the recyclability and reusability of nanomaterials in the superhydrophobic coating are of both environmental and economical significance.

In terms of oil-water separation, current methods mainly focus on making super-hydrophobic/oleophilic mesh, ${ }^{48-50}$ fabric, $^{36,51}$ sponge $^{3,37}$ or membranes ${ }^{52}$ to collect oils. 
However, when the amount of water is extremely small compared with that of oil (e.g., several drops were mixed in a large oil tank), it would be very inefficient if using a membrane to filter all the oil/water mixture in the tank. In this condition, it is straightforward to remove water from oil using an under-oil-superhydrophobic surface.

Ultra high molecular weight polyethylene (UHMWPE) is usually used as an orthopaedic bearing material in total joint replacement due to its wear resistance, low friction, high impact strength and chemical stability. ${ }^{53}$ Taking advantage of the properties of UHMWPE, three series of coatings were fabricated by mixing UHMWPE with hydrophobic $\mathrm{SiO}_{2}(\sim 30 \mathrm{~nm})$ (i.e., $\mathrm{SiO}_{2}$-UHMWPE series), $\mathrm{NiO}(\sim 50 \mathrm{~nm}$, modified by FAS-17 to create a low energy surface) (i.e., NiO-UHMWPE) nanoparticles, or both of them (i.e., NiO-SiO2-UHMWPE) to obtain mechanically durable superhydrophobic coating with low wear loss/thickness. The suspension was poured onto a variety of different shaped substrates to form a water repellent surface. The treated surfaces exhibited outstanding mechanical stabilities against abrasion to sandpaper, blade scratch, tape-peeling, and maintained its superhydrophobicity after being exposed in a high humidity environment $\left(60{ }^{\circ} \mathrm{C}, 90 \%\right.$ relative humidity), after UV irradiation as well as 50 high/low temperature cycles. The coating could be bent, folded and deformed into different shapes, and could be prepared on steel, aluminum, copper, titanium alloys and polycarbonate (PC) of any size and shape. The low energy nanomaterials of the coating could be reused, indicating that a recycling durable system for water proofing has been developed. In addition, this coating is superhydrophobic when immersed in oils, based on which, we have designed two high-efficient systems to remove water from large amount of oils - velocity-controlled stirring and inverted cone systems. Small water drops converge to one bigger drop on the under-oil-superhydrophobic surface through stirring or an inverted cone, and were then removed in the form of ice after cooled by liquid nitrogen. The 
oil purification systems can find applications in removing water from large fuel tanks and even airplanes.

\section{Experimental Section}

Materials. Ultra high molecular weight polyethylene $(5,000,000$ molecular weight, average diameter of $150 \mu \mathrm{m}$, UHMWPE) was purchased from Celanese Holding Co., Ltd, China. Steel, aluminum, copper, titanium alloys $\left(50 * 20 * 0.3 \mathrm{~mm}^{3}\right)$ and steel sheet (thickness $=0.2 \mathrm{~mm}$ ) were purchased from local stores. All other chemicals were from Sigma-Aldrich (analytical-grade reagents) and used as received.

Preparation of hydrophobic silica $\left(\mathrm{SiO}_{2}\right)$ nanoparticles. Firstly, $3 \mathrm{~mL}$ of ammonium hydroxide (25\%) was added to $50 \mathrm{~mL}$ of ethanol and stirred vigorously at $60{ }^{\circ} \mathrm{C}$ for $30 \mathrm{~min}$. Then $3 \mathrm{~mL}$ of tetraethylorthosilicate (TEOS) and $2.4 \mathrm{~mL}$ of trimethylethoxysilane (TMES) were mixed and added to the solution dropwise.

Preparation and modification of oxide nickel (NiO) nanoparticles. Firstly, $24 \mathrm{~g}$ of nickel sulfate hexahydrate $\left(\mathrm{NiSO}_{4} \cdot 6 \mathrm{H}_{2} \mathrm{O}\right)$ was added to $600 \mathrm{~mL}$ of deionized water and stirred at $75{ }^{\circ} \mathrm{C}$ for $20 \mathrm{~min}$. Secondly, $2.3 \mathrm{~g}$ of sodium borohydride $\left(\mathrm{NaBH}_{4}\right)$ was dissolved in $300 \mathrm{~mL}$ of deionized water, and was added dropwise into the $\mathrm{NiSO}_{4}$ solution. Then the particles were collected and washed with deionized water and ethanol at least three times to eliminate the residual solution, and then they were immersed in deionized water for $10 \mathrm{~h}$. Finally, the particles were dried at $50{ }^{\circ} \mathrm{C}$. The obtained particles were soaked in 2 wt $\%$ 1H,1H,2H,2H-perfluorodecyltriethoxysilane $\left(\mathrm{C}_{10} \mathrm{~F}_{17} \mathrm{H}_{4} \mathrm{Si}\left(\mathrm{OCH}_{2} \mathrm{CH}_{3}\right)_{3}, \mathrm{FAS}-17\right)$ in hexane at $40{ }^{\circ} \mathrm{C}$ for $3 \mathrm{~h}$, then were thoroughly cleaned with hexane and desiccated in a drying oven.

Fabrication of UHMWPE based coating. $\mathrm{NiO}$ (modified by FAS-17), hydrophobic $\mathrm{SiO}_{2}, 0.25 \mathrm{~g}$ of UHMWPE, and $50 \mathrm{~mL}$ of decahydronaphthalene (solvent) were mixed and stirred at $160{ }^{\circ} \mathrm{C}$ for 1 
h. Then, the solution (at $160{ }^{\circ} \mathrm{C}$ ) was poured on the substrates (pre-treated by oxygen plasma) and dried at $100{ }^{\circ} \mathrm{C}$ for $2 \mathrm{~h}$. During the drying process, the solvent was collected through a system of condensate recovery. The whole process was conducted in the fume hood. The addition of $\mathrm{NiO}$ was varied from 2 to $5 \mathrm{~g}\left(0.5 \mathrm{~g}\right.$ as an unit), while the addition of $\mathrm{SiO}_{2}$ was varied from 0.4 to $1.6 \mathrm{~g}(0.2 \mathrm{~g}$ as an unit). The coatings prepared with only $\mathrm{NiO}$ or $\mathrm{SiO}_{2}$ were denoted as NiO-UHMWPE and $\mathrm{SiO}_{2}$-UHMWPE series, respectively. While those prepared with both the $\mathrm{NiO}$ and $\mathrm{SiO}_{2}$ were denoted as $\mathrm{NiO}-\mathrm{SiO}_{2}-\mathrm{UHMWPE}$ series.

Sandpaper abrasion. The resultant coating (steel substrate weight $=25 \mathrm{~g}, 50 * 20 * 0.4 \mathrm{~mm}^{3}$ ) was loaded with $200 \mathrm{~g}$ and faced-down onto 200 grid $\mathrm{SiC}$ sandpaper (calculated pressure $=2.25 \mathrm{kPa}$ ), and moved along the ruler for $22.5 \mathrm{~cm}$. When the sample reached the edge of the sandpaper, it was pulled backward; this process was defined as 1 cycle, and the coating was abraded for $45 \mathrm{~cm}$. In the next cycle, the sandpaper was moved $2 \mathrm{~cm}$ away from the previous trace in order to guarantee that the sample was abraded by a coarse sandpaper surface. The wear thickness/loss is calculated as following:

$$
\text { Wear loss }=T_{o}-T_{a}
$$

where $T_{o}$ and $T_{a}$ denote the thickness of original and abraded coating.

Blade scratching. Blade scratching was carried out using a sharp knife to scratch the prepared coating. The coating was scratched into many grids with size of $5 \times 5 \mathrm{~mm}^{2}$.

Tape-peeling test. Testing procedures were generally based on the method B of ASTM D3359-09 ${ }^{\varepsilon 2}$. The coating was pressed by $1 \mathrm{Kg}$ loading $(\sim 14 \mathrm{kPa})$ with adhesive tape (Scotch-600 tape, a thin eraser was attached under the loading so as to ensure good contact between the tape and coating), and then the tape was peeled off.

Bending and deforming. 1) repeated folding: the coating was fabricated on PC film or flat steel 
sheet, and the treated surface was bent forwards and backwards, from $-90^{\circ}$ to $90^{\circ}$ for several times, this process was defined as 1 cycle; Only the treated PC was folded for multiple times, because the folding would lead to the fatigue fracture of steel sheets; 2) deformation: the treated sheet was bent and rolled into a cylindrical shape (tube).

Environmental tests. After abrasion test, the coating was subjected to the environmental tests. Humidity test was carried out in a humidity chamber with a constant temperature of $60{ }^{\circ} \mathrm{C}$ and a wind of $90 \%$ relative humidity during the whole process.

After humidity test, the prepared coating was exposed in a UV chamber with a $500 \mathrm{~W}$ (900 $\mu \mathrm{Wcm}^{-2}$ ) ultraviolet high-pressure mercury lamp (Belsri/UV model, Beijing Institute of Electric Light Source) up to $8 \mathrm{~h}$.

After UV irradiation test, the coating was put into high/low alternating temperature environment. Sample was put at $-30{ }^{\circ} \mathrm{C}$ for $1 \mathrm{~h}$, and then the temperature increased to $60{ }^{\circ} \mathrm{C}$ and kept for $1 \mathrm{~h}$; this process was defined as cycle 1. Fig. S6d shows the relationship between the time and temperatures.

Recycling process. The mixture of decahydronaphthalene, UHMWPE, and coating debris (peeled off from the coating by a chisel) were stirred at $160{ }^{\circ} \mathrm{C}$ for $1 \mathrm{~h}$. Then, the solution (at $160{ }^{\circ} \mathrm{C}$ ) was poured on the substrates and dried at $100{ }^{\circ} \mathrm{C}$. The mass ration of UHMWPE, debris and decahydronaphthalene was 1: 17.5: 224. During the drying process, the solvent was collected through a system of condensate recovery. The whole process should be conducted in fume hood.

Oil purification. Hexane (98\%, Sigma-Aldrich), gasoline (92\#, Sinopec) and kerosene (Sinopec) were used as oils. The water was dyed blue with methylene blue. $0.4 \mathrm{~mL}$ water was added into 50 $\mathrm{mL}$ oil. The water collection efficiency was calculated as following:

$$
\mathrm{R}(\%)=(\mathrm{Mc} / \mathrm{Mo}) \times 100 \%
$$


where Mo and Mc denote the water mass in the initial oil/water mixture and collected water.

Characterizations. Scanning electron microscope (SEM, Hitachi S4800) was employed to determine surface morphologies. Distributions of $\mathrm{C}, \mathrm{Si}$ and $\mathrm{Ni}$ elements were determined by energy-dispersive spectroscope (EDS, Oxford) in mapping mode. True colour confocal microscope system (Axio CSM 700) was used for morphology observation, surface roughness and the coating thickness measurements. X-ray photoelectron spectroscopy (XPS, PHI Quantera II) was performed with monochromatic Al-K $\alpha$ source. High-resolution scans were done with beam angle of $45^{\circ}$ at a pass energy of $55 \mathrm{eV}$ and resolution of $0.1 \mathrm{eV}$ per step. Fourier transform infrared (FTIR, Nicolet IS-10) spectra were recorded in the range $4000-1250 \mathrm{~cm}^{-1}$. Contact angles were measured with a 5 - $\mu \mathrm{L}$ droplet of deionized water at ambient temperature on a contact angle measurement instrument (JC2000D2, China). Reported data were averages of 6 measurements at different places on the sample. High-speed camera (IDT Y4) was used to record the bouncing process of droplets at 1000 frames per second under light intensity of $20000 \mathrm{~lm}$. A zoon lens (Navitar Zoom 6000) attached to the camera through an adapter (Navitar 2.0X) was used to magnify the area. A $5 \pm 0.2 \mu \mathrm{L}$ droplet was dropped from a height of $51 \mathrm{~mm}$ through a micro-syringe, the speed when the droplet impacted the surface was $\sim 1 \mathrm{~ms}^{-1}$ calculated by gravimetric calculation. The humidity resistance ability was investigated in a humidity chamber (RGDS-500, China).

\section{Results and Discussion}

\section{Fabrication of superhydrophobic coating.}

The combination of superhydrophobicity and low wear thickness/loss is crucial for practical use. In order to systematically study the wear durability of the UHMWPE based coatings, three series of coatings were developed with respect to the different nanoparticles added: NiO-UHMWPE, 
$\mathrm{SiO}_{2}$-UHMWPE and NiO-SiO 2 -UHMWPE. After being abraded for $630 \mathrm{~cm}$ on 200 grid sandpaper under $2.25 \mathrm{kPa}$, the wear thickness/loss and wettabilities of the coatings are displayed in Fig. 1. For the NiO-UHMWPE series (Fig. 1a), the wear thickness and contact angle (CA) increased along with the addition of $\mathrm{NiO}$, and stayed relatively stable after a critical point (i.e., $\mathrm{NiO} \geq 3.5 \mathrm{~g}$ ). As for the $\mathrm{SiO}_{2}$-UHMWPE series (Fig. 1b), the wear thickness and hydrophobicity were positively related with the addition of $\mathrm{SiO}_{2}$, thus along with the increase of $\mathrm{SiO}_{2}$, the coating exhibited superhydrophobicity when $\mathrm{SiO}_{2} \geq 1.4 \mathrm{~g}$ (blue area in Fig. 1b). Images of contact/sliding angles of the two systems are shown in Fig. S1 in Supporting Information. Although $\mathrm{SiO}_{2}-\mathrm{UHMWPE}$ system showed superior water repellency in the blue area, the wear loss was too high $(>224 \mu \mathrm{m})$, which means the $\mathrm{SiO}_{2}$-UHMWPE coating is easy to be worn out. In order to balance the mechanical durability and superhydrophobicity, we combined the $\mathrm{NiO}, \mathrm{SiO}_{2}$ and UHMWPE together, and analysed the wettability (Fig. 1c-e) as well as wear resistance (Fig. 1f) to find out an acceptable proportion among $\mathrm{NiO}, \mathrm{SiO}_{2}$ and UHMWPE. Concerning the requirement of hydrophobicity and low wear thickness, a certain amount of $\mathrm{NiO}(2.5 \sim 3.5 \mathrm{~g}$, Fig. 1a) was chosen in the NiO-SiO2-UHMWPE series; in this selected area (Fig. 1a), the coating exhibited relatively high contact angle $\left(140 \sim 150^{\circ}\right)$ and low wear loss $(110 \sim 160 \mu \mathrm{m})$. Fig. If presents the wear thickness/loss of $\mathrm{NiO}_{-} \mathrm{SiO}_{2}-\mathrm{UHMWPE}$ after being abraded for $630 \mathrm{~cm}$ (initial thickness, $280 \mu \mathrm{m}$ ), the blue area was drawn based on the wettabilities of the coatings as shown in Fig. 1c-e. In the $\mathrm{NiO}-\mathrm{SiO}_{2}$-UHMWPE system, the A1 coating (the tip point, Fig. 1f) is the best combination as it possesses both superior water repellency $\left(\mathrm{CA}=162^{\circ}, \mathrm{SA}=3^{\circ}\right)$ and low wear loss $(\sim 164 \mu \mathrm{m}$ after $630 \mathrm{~cm}$ abrasion). Compared with coatings in NiO-UHMWPE system (Fig. 1a), the A1 shows outstanding superhydrophobicity; the wear loss in the lotus area of $\mathrm{SiO}_{2}-\mathrm{UHMWPE}$ is more than $224 \mu \mathrm{m}$ after $630 \mathrm{~cm}$ abrasion, which is higher than that of A1. Thus, by analyzing the wear 
thickness and wettabilities of NiO-UHMWPE, $\mathrm{SiO}_{2}-\mathrm{UHMWPE}$, and $\mathrm{NiO}-\mathrm{SiO}_{2}-\mathrm{UHMWPE}$ coatings, we successfully designed a superhydrophobic coating with superior mechanical durability. Based on the composition of $\mathrm{A} 1$ (3g of $\mathrm{NiO}, 0.8 \mathrm{~g}$ of $\mathrm{SiO}_{2}$ in Fig. 1f), $\mathrm{A} 2(3 \mathrm{~g}$ of $\mathrm{NiO})$ and $\mathrm{A} 3\left(0.8 \mathrm{~g}\right.$ of $\left.\mathrm{SiO}_{2}\right)$ are marked in Fig 1a and b, as A1 could be generally regarded as the combination of A2 and A3. Fig. S2 shows the coating process of A1: the decahydronaphthalene solution of UHMWPE, NiO and $\mathrm{SiO}_{2}$ nanoparticles were poured (at $160{ }^{\circ} \mathrm{C}$ ) on substrates of different sizes and shapes (e.g. rectangular, circular, and cross shapes). Water repellency was observed on the resultant substrates after the coating had dried (during the drying process, the solvent was collected through a system of condensate recovery), as shown in Movie S1 in Supporting Information, such that the water column rebounded and droplets slipped off the surface. 

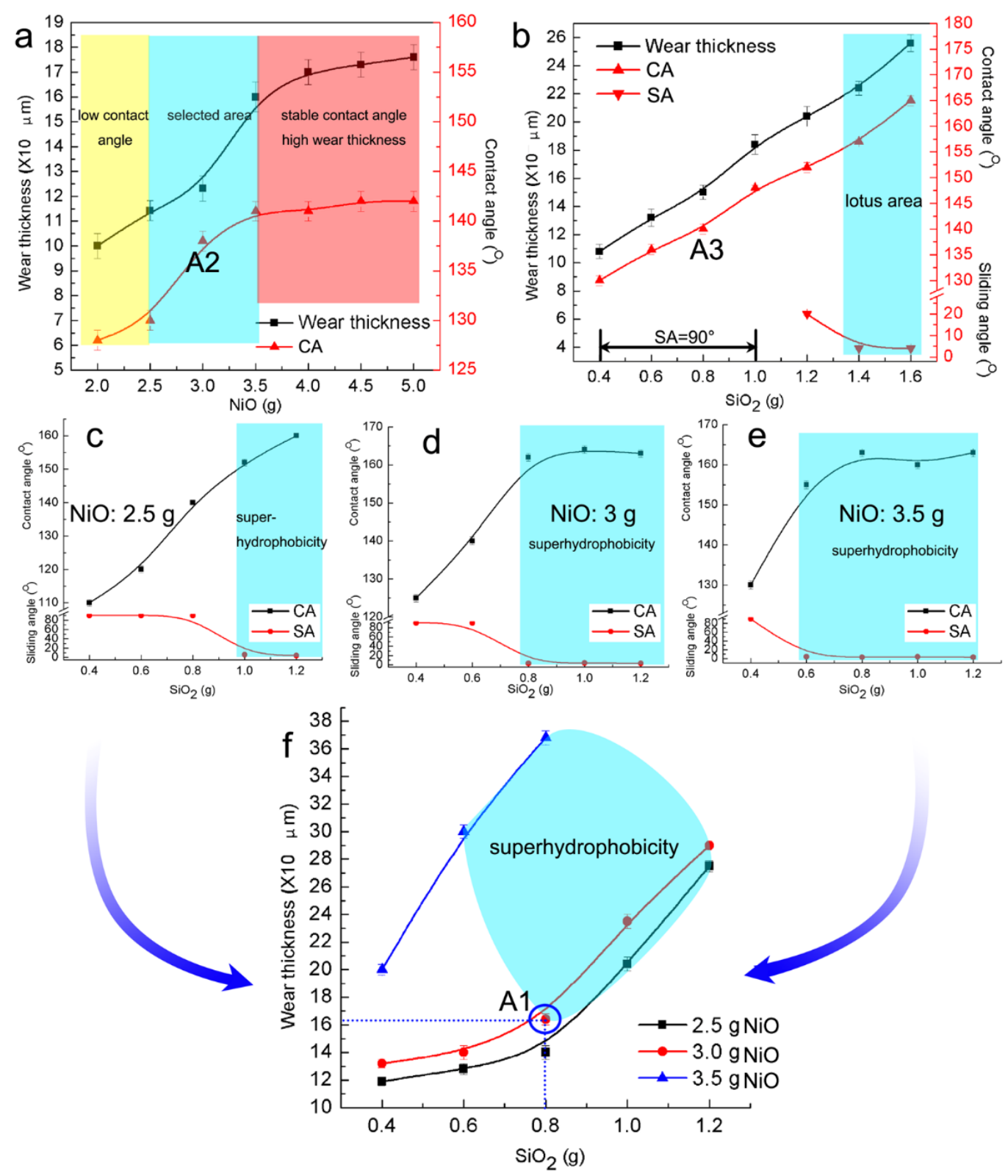

Figure 1. After abrasion of $630 \mathrm{~cm}$, the wear thickness and water wettabilities of (a) NiOUHMWPE, (b) $\mathrm{SiO}_{2}$-UHMWPE and (c-f) $\mathrm{NiO}-\mathrm{SiO}_{2}$-UHMWPE coatings on steel substrates. Blue areas in (b-e) represent the coatings are superhydrophobic: along with the increase of $\mathrm{SiO}_{2}$, the water repellency increased and finally the coating exhibited extremely low water affinity. The wear thickness of $\mathrm{NiO}-\mathrm{SiO}_{2}-\mathrm{UHMWPE}$ is shown in $\mathbf{f}$, and blue area was drawn based on its wettabilities in c-e; the tip point, $\mathrm{A} 1\left(0.8 \mathrm{~g}\right.$ of $\mathrm{SiO}_{2}, 3 \mathrm{~g}$ of $\left.\mathrm{NiO}\right)$, exhibited superior water repellency $\left(\mathrm{CA}=162^{\circ}\right.$, $\left.\mathrm{SA}=3^{\circ}\right)$ compared with the NiO-UHMWPE system, and less wear loss $(\sim 164 \mu \mathrm{m})$ compared with the superhydrophobic area in the $\mathrm{SiO}_{2}$-UHMWPE system. 


\section{Characterization of A1 coating.}

A complete analysis [e.g., SEM, Fourier transform infrared spectrum (FTIR), XPS] of the $\mathrm{SiO}_{2}$ and $\mathrm{NiO}$ nanoparticles is presented in Fig. S3. Scanning electron microscopy (SEM) (Fig. 2a-b) indicate the nanoscale structures, and microscale asperities could be observed on the true colour confocal microscopy (Fig. 2c) images, indicating the micro/nano hierarchical structures of A1 coating. Compared with A2 and A3 (Fig. S4), the surface of A1 exhibited a more textured morphology. Fig. 2e shows the cross-section of the coating, it is obvious that this area is covered with polymer. Fig. $2 \mathrm{~d}$ and $\mathrm{f}$ shows the energy-dispersive spectroscopy (EDS) mapping images of the surface and cross-section of the coating, the distributions of $\mathrm{Ni}, \mathrm{Si}$ and $\mathrm{C}$ were uniform, suggesting that the $\mathrm{NiO}(\sim 50 \mathrm{~nm}), \mathrm{SiO}_{2}(\sim 30 \mathrm{~nm})$ nanoparticles and UHMWPE were well mixed inside and outer the surface of A1. The EDS spectra are presented in Fig. S5. Due to the accuracy of EDS, the content of $\mathrm{F}$ on the surface and cross-section can barely be detected, indicating that the large amount of $\mathrm{Si}$ or $\mathrm{C}$ elements is not due to the surface modification of FAS-17 $\left(\mathrm{C}_{10} \mathrm{~F}_{17} \mathrm{H}_{4} \mathrm{Si}\left(\mathrm{OCH}_{2} \mathrm{CH}_{3}\right)_{3}\right.$, see Experimental Section) on $\mathrm{NiO}$, but mainly due to the $\mathrm{SiO}_{2}$ and UHMWPE. The schematic structure of the coating is presented in Fig. $2 \mathrm{~g}$. The low surface free energy nature of the coating was confirmed by $-\mathrm{CF}_{3}$ and $-\mathrm{CF}_{2}$ groups observed using $\mathrm{X}$-ray photoelectron spectroscopy (XPS, Fig. 2h), which can be attributed to the FAS-17 that contacted on the NiO. Thus, the dual-scaled nanoparticles and the polymer with low surface free energy, afforded a coating that was super water repellent by mimicking the Lotus leaf. ${ }^{14}$ Fig. $2 \mathrm{i}-\mathrm{j}$ show time-lapse photographs of water droplets impacting $(\sim 5 \mu \mathrm{L})$ on bare steel and treated steel surfaces using a high speed camera. When a water droplet impacted the treated surface at a speed of $\sim 1 \mathrm{~ms}^{-1}$ (height $=5.1 \mathrm{~cm}$ ), it bounced within $14 \mathrm{~ms}$ without wetting the surface, suggesting superhydrophobicity. In contrast, for the bare steel substrate, the water droplet stayed on the surface once they contacted it. 
Fig. S6 shows the water bouncing process on treated copper, aluminum, titanium alloys and polycarbonate (PC) film. Thus, the coating could be prepared on most commonly used metals, as well as some polymer surfaces, in any size and shape, indicating that this method can be widely used.
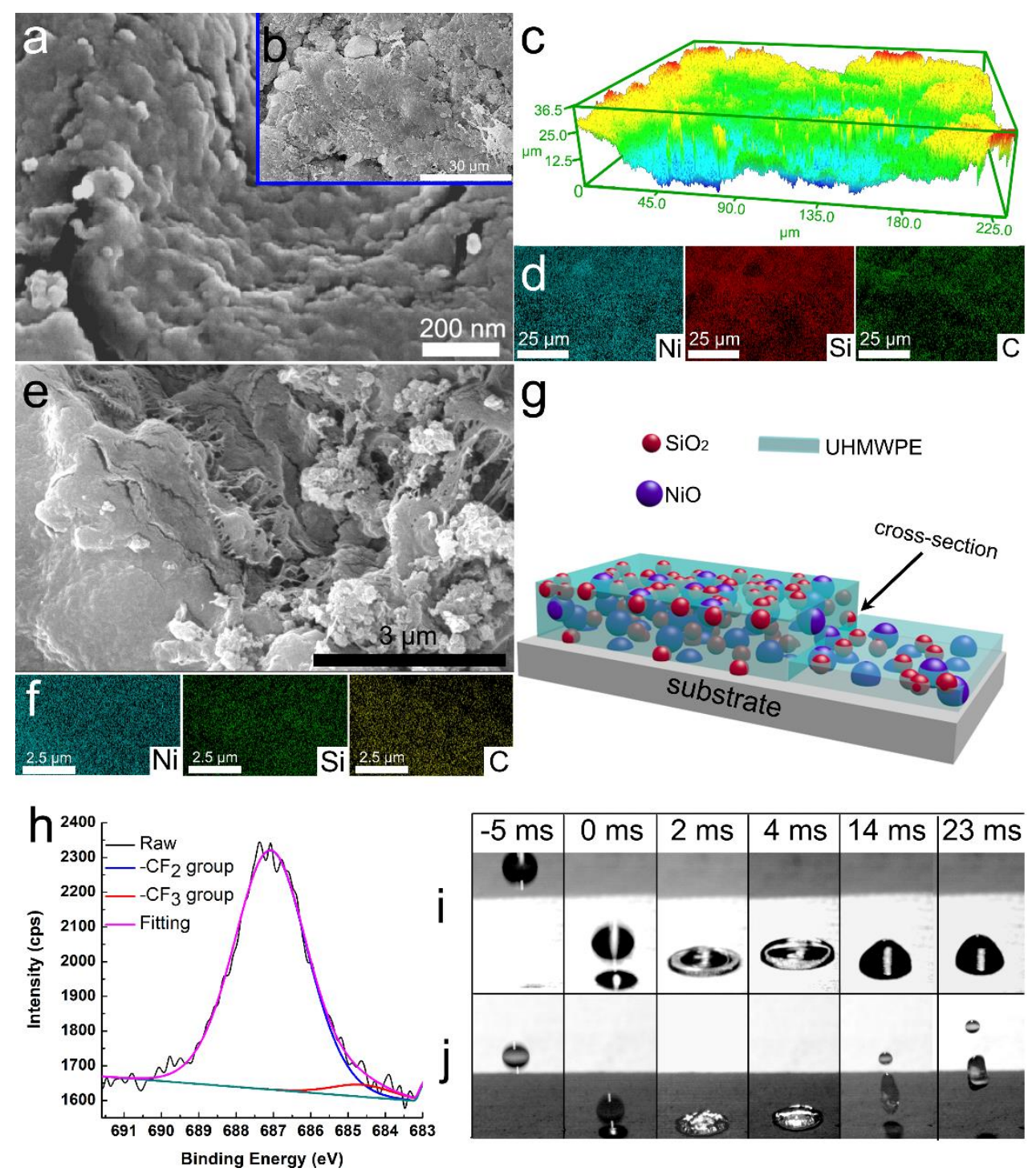

Figure 2. Characterization of A1. (a, b) SEM, (c) true colour confocal microscopy and (d) EDS mapping images of $\mathrm{Si}, \mathrm{Ni}$ and $\mathrm{C}$ elements on the surface of $\mathrm{A} 1$; (e) SEM and (f) EDS mapping images of cross-section area; (g) Schematic of coating structure; (h) XPS high-resolution spectrum of $\mathrm{F} 1 \mathrm{~s}$, resolved into two components, $-\mathrm{CF}_{2}(687.07 \mathrm{eV})$ and $-\mathrm{CF}_{3}(684.62 \mathrm{eV})$. Time-lapse 
photographs of water droplets impacting on (i) bare steel, (j) treated steel surfaces. Droplet sizes, $\sim 5$ $\pm 0.2 \mu \mathrm{L}$. Impact velocity, $\sim 1 \mathrm{~ms}^{-1}$.

\section{Mechanical durability, deformability and environmental tests.}

The micro/nano structures of superhydrophobic surfaces are usually subject to mechanical damage, and it is the main reason that hinders the practical applications. Here we further tested the mechanical strength of A1 using the methods of sandpaper abrasion, blade scratching, tape-peeling, bending and deforming. Fig. 3a and $\mathbf{b}$ shows the water contact/sliding angle as a function of abrasion distance, and the schematic of the abrasion process is also displayed. The coated steel surface was placed faced-down onto 200 grid SiC sandpaper under loading of $200 \mathrm{~g}$, (i.e., calculated pressure $=2.25 \mathrm{kPa}$ ), and moved forward for over $965 \mathrm{~cm}$ (Movie S2). The contact angles varied between $166^{\circ}$ and $153^{\circ}$, and sliding angles were between $4^{\circ}$ and $7^{\circ}$ through the abrasion cycles, and the wetting behavior did not significantly change; Fig. $3 \mathrm{c}$ shows contact/sliding angle, and water droplets bouncing on the coated surface after $965 \mathrm{~cm}$ of movement for the sandpaper test. The bouncing behavior after the sandpaper test, exhibited little difference compared with that before abrasion, indicating that the coating could function after severe mechanical damage; meanwhile, the wear thickness/loss after the abrasion was $251.2 \mu \mathrm{m}$, indicating that the coating has superior wearability.

UHMWPE possesses superior mechanical properties, such as superior impact strength, high wear resistance and low friction. Compared with the $\mathrm{SiO}_{2}$ and $\mathrm{NiO}$ nanoparticles (Fig. S3), the nano particles of the prepared coating were covered and embedded in the polymer (Fig. 2a) and a large area of polymer could be observed, as shown in Fig. $2 \mathrm{~b}$. This suggests that the UHMWPE serves as both the protection and adhesive, such that it has reinforced the binding force between the nano 
particles. On the other hand, the low friction nature of UHMWPE could reduce the wear during the abrasion, so that the micro/nano hierarchical structures were not easily abraded. Meanwhile, the intrinsic hydrophobic nature of UHMWPE could also improve the water repellency of the resultant coating. After the abrasion test, we further analysed the surface structures and chemistry as shown in Fig. S7: the worn surface was still covered by the UHMWPE with a highly textured surface morphology. This is because the uniform structure inside and outer the coating as shown in Fig. $2 \mathrm{~g}$, the $\mathrm{SiO}_{2}$ and $\mathrm{NiO}$ are well-distributed inside the coating, thus the cross-section area exhibited the similar morphologies and chemical compositions with one before abrasion, which leads to the same wetting behavior (i.e., superhydrophobicity). Thus, by combining the low free energy nanoparticles and UHMWPE, superior mechanical durability could be yielded for the superhydrophobic coating. 

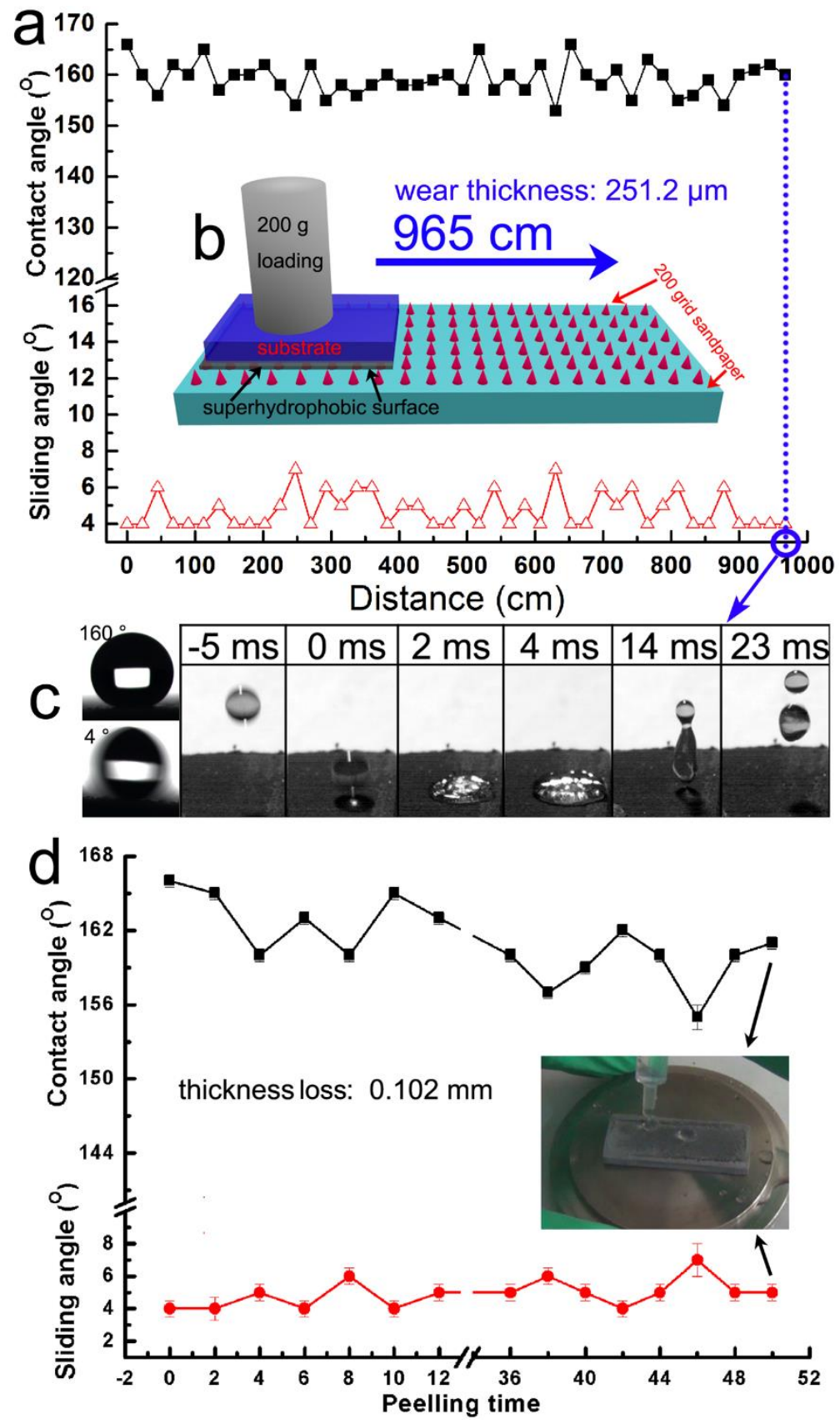

Figure 3. Mechanical durability of A1. (a) Plot of the water contact/sliding angles as a function of the distance of sandpaper abrasion. (b) Schematic of abrasion test. (c) Images of contact/sliding angles, and time-lapse photographs of water droplets bouncing on abraded coating. Droplet sizes, $\sim 5 \pm 0.2 \mu \mathrm{L}$. Impact velocity, $\sim 1 \mathrm{~ms}^{-1}$. (d) Plot of the water contact/sliding angles as a function of tape-peeling times. 
The coating also possessed superior adhesion to the substrates. Fig. 3d shows the contact/sliding angles as a function of tape-peeling times. The surface stayed superhydrophobic (i.e., $\mathrm{CA}=161^{\circ}, \mathrm{SA}=5^{\circ}$ ) after 50 times peeling, and the thickness loss of the coating is about $102 \mu \mathrm{m}$ (for details, see Movie S2), suggesting outstanding mechanical durability. On the other hand, the strong adhesion of the coating could also be reflected through the abrasion test: the coating with extra loading was moved forward on the coarse sandpaper, instead of being peeled from the substrate, it was abraded and debris could be observed. Fig. S8 shows the SEM and 3D morphologies of the coating after tape-peeling, and the surface still exhibited highly textured structures. Surface energy could greatly influence the adhesion of coating on a substrate. ${ }^{54,55}$ The surface energies of steel are usually over hundreds or even thousands of $\mathrm{mJ} / \mathrm{m}^{2}$, which is much higher than polymers, ${ }^{56}$ such as UHMWPE; and the plasma treatment of metal substrate could increase the surface energy effectively ${ }^{54}$ which has been widely used to improve the adhesion of UHMWPE films. ${ }^{57-59}$ According to K.L. Mittal's theory, an organic polymer in the liquid state could usually exhibit a low- or zero contact angle on high energy substrates, and resulting in better adhesion. ${ }^{56}$ Furthermore, the coating could resist blade scratching without losing its superhydrophobicity (Movie S3).

A superhydrophobic surface that could be bent or deformed and retain the superior water repellency would be vitally important for a wide range of applications. Two deformation tests of the coated surfaces were developed (for details, see Movie S4): a) repeated folding tests-the coating treated on PC still exhibited extreme water repellency and water droplets rolled away easily over 100 folding cycles (Fig. 4a), indicating that the coating could resist severe mechanical bending. Fig. 4b-d shows the superhydrophobic coating on steel sheets, which were bent into different shapes. It was observed that water droplets on the kink regions still maintained a spherical shape; b) 
deformation tests - the treated steel sheet was deformed into a tube, and the superhydrophobicity was still retained (Fig. 4e-f). Meanwhile, Fig. S9 shows that for the coating on a PC film, due to the elastic nature of the PC film, the surface was pushed down when droplets were added, and the coating swung with the PC film, showing good flexibility. The surface morphologies of A1 after deformation are shown in Fig. S8, and the surface did not undergo essential changes compared with one before 100 folding cycles. The UHMWPE is considered to possess low hardness and Young's modulus. ${ }^{60}$ In this case, it could provide resilience and is favorable for the deformable ability of the coating. Thus, the addition of UHMWPE could not only improve the wearable ability, but also endow the nanoparticles (i.e., $\mathrm{SiO}_{2}$ and $\mathrm{NiO}$ ) with superior resilience. The dual-scaled nanoparticles, together with UHMWPE, have achieved both mechanically durable and flexible abilities. 

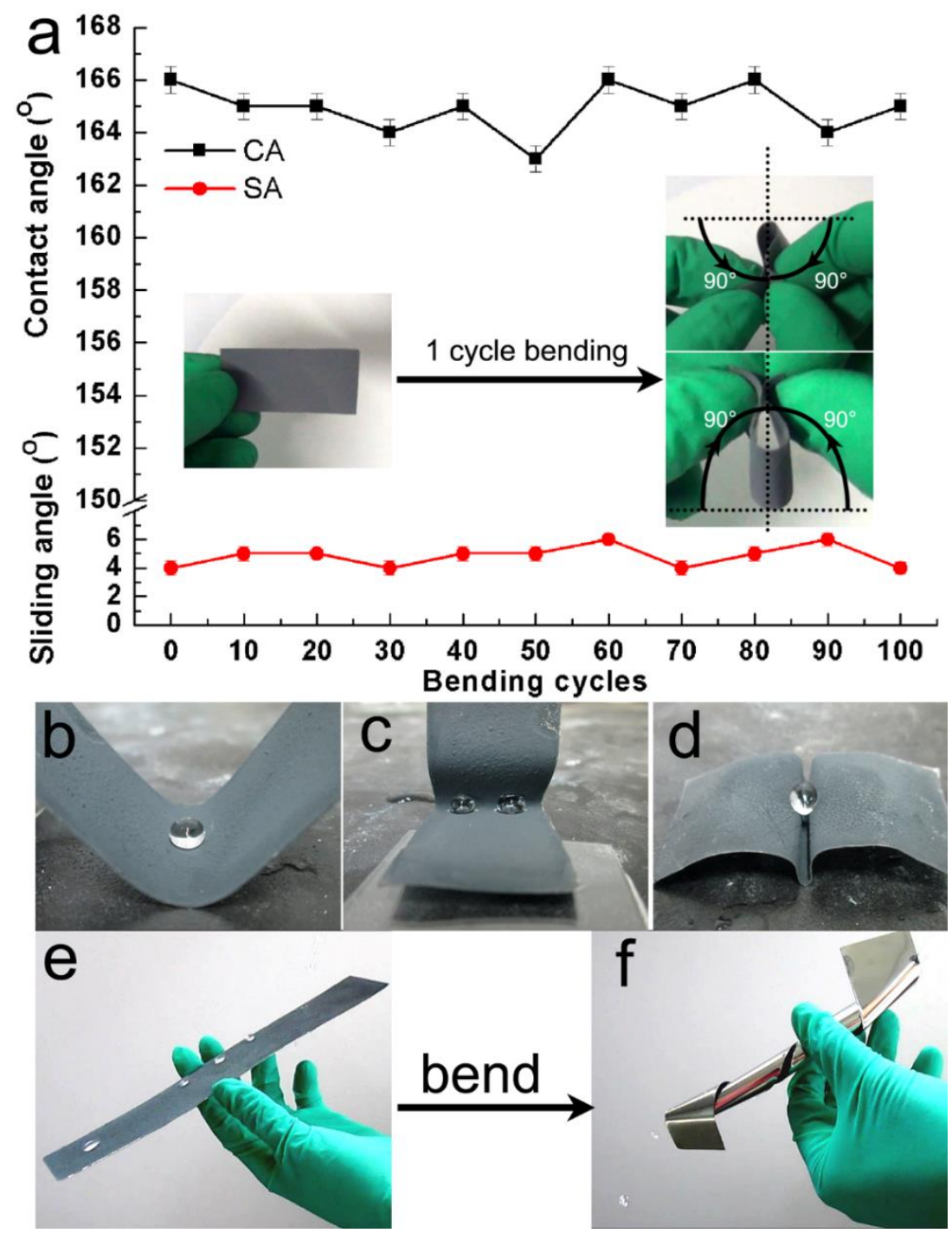

Figure 4. Deformability/flexibility of A1. (a) Plot of water contact/sliding angles as a function of bending times. (b-d) Water droplets on coating prepared on steel sheets. The water in the kink regions stayed spherical. (e, f) After being deformed into cylindrical shape, droplets could still roll through the middle.

In practical conditions, functional surfaces are subject to not only mechanical abrasion, but also to some extreme conditions for multiple-cycles, such as a warm and humid environment, UV light exposure and an alternant atmosphere between low and high temperatures. After abrasion for over $965 \mathrm{~cm}$, the A1 coating was used in the environmental tests (see details in Experimental 
Section), which consisted of three steps: Step 1, the coating was put into a chamber at $60{ }^{\circ} \mathrm{C}$ and with $90 \%$ relative humidity $(\mathrm{RH})$ for 20 days; then in Step 2, the coating from Step 1 was exposed under UV irradiation $\left(900 \mu \mathrm{Wcm}^{-2}\right)$ for $8 \mathrm{~h}$; in Step 3, the coating from Step 2 was put in an alternating high/low temperature $\left(-30 \sim 60^{\circ} \mathrm{C}\right)$ environment for 50 cycles. Fig. S10 a-c presents the water contact/sliding angles during the whole testing process, where it was found that the contact angle stayed above $155^{\circ}$, and sliding angle was below $7^{\circ}$. Fig. S10d shows the temperature as a function of time during the high/low temperature cycles in Step 3. Fig. S10e shows the bouncing process of water droplets on the surface after the 3-step environmental tests, the droplet still bounced and completely left the surface, indicating that the coating retained superhydrophobicity.

Recycling of nanoparticles. We have shown the superior durability of the coating through the aforementioned tests, including abrasion, blade scratching, tape-peeling, deforming and environmental tests. However, to take into account environmental concerns and make full use of raw materials, we designed a strategy to recycle the nanoparticles of superhydrophobic coatings that have been treated on substrates, which would reduce or even overcome any potential problems caused by the low surface energy materials. ${ }^{47,61,62}$ Fig. 5 and Movie S5 demonstrate the recycling process. The debris that peeled from the coating by a chisel was mixed with extra UHMWPE and then put into the solvent; the resultant suspension was stirred at $160{ }^{\circ} \mathrm{C}$ for $1 \mathrm{~h}$ and then returned to the initial liquid-formation of coating. The coating suspension (at $160{ }^{\circ} \mathrm{C}$ ) was then poured onto a substrate and dried at $100{ }^{\circ} \mathrm{C}$ for $2 \mathrm{~h}$ (during the drying process, the solvent was collected through a system of condensate recovery), to make the superhydrophobic surface. The droplet stayed spherical $\left(\right.$ contact angle $\left.=157^{\circ}\right)$ on recycled coating, and rolled off easily (sliding angle $=4^{\circ}$ ) According to the time-lapse photographs of water droplets bouncing on the recycled coating, the 
bouncing time did not significantly change compared with the initial treated steel surface (Fig. 2j), indicating that the low energy materials could be recycled and reused.

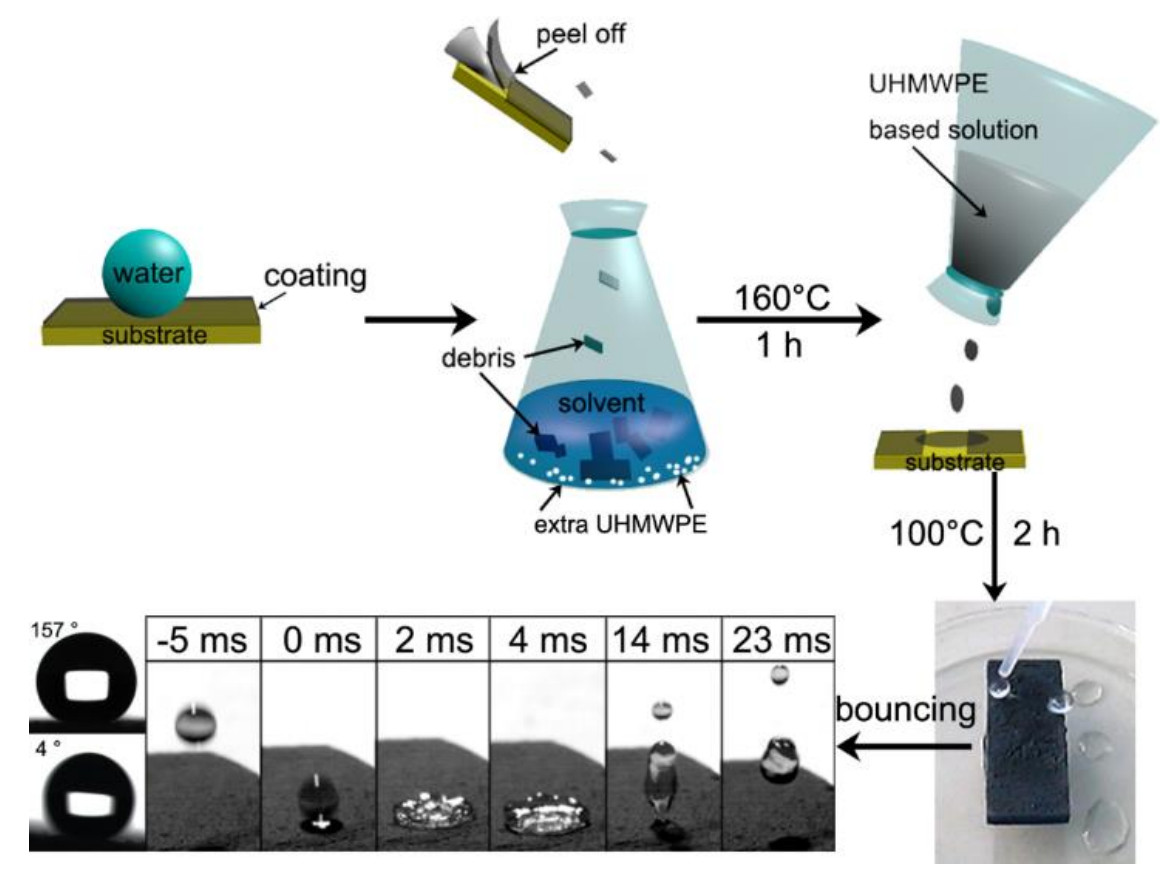

Figure 5. Schematic of the recycling process. The A1 coating was peeled off by a chisel, dissolved into suspension with UHMWPE at $160{ }^{\circ} \mathrm{C}$, and then poured on steel substrate and dried to form the water repellent surface. Droplet bounced on recycled coating, indicating the reconstructed coating maintained superhydrophobicity. Recycled coating exhibited high contact angle $\left(157^{\circ}\right)$ and low sliding angle $\left(4^{\circ}\right)$. Droplet sizes, $\sim 5 \pm 0.2 \mu \mathrm{L}$. Impact velocity, $\sim 1 \mathrm{~ms}^{-1}$.

\section{Water removal in oil.}

The coating can be readily wetted by oils (Fig. S11), and this enables the oil to occupy the air pockets of the coating when immersed in oil; in this condition, the coating retains superhydrophobicity under oil. Fig. 6a shows the water drops formed spherical and rolled off the coated surface that was immersed in gasoline. While on the bare steel sheet, the droplet stayed on the slope. Based on the superhydrophobicity under oil, two systems were designed to remove water 
from oil. a) the stirring system, which is designed for the fuel tanks with flat bottom (for details, see Movie S6). Upon oil (gasoline) immersion, water formed spheres on the coated bottom instead of wetting the surface as shown in Fig. $6 \mathrm{~b}$. The small drops (diameter: $0.5 \sim 1 \mathrm{~mm}$ ) would converge when given a centripetal force through velocity-controlled stirring (Fig. 6c-d). When the small drops became one big drop, liquid nitrogen was added to cool the drop into an ice ball (Fig. 6e), and then the ice ball can be easily removed (Fig. 6f). While on the bare steel substrate under gasoline, the small droplets pinned and could not move when the centripetal force was applied (Movie S6). Due to the flexibility of the coating, the treated surface can be bent into an inverted cone to gather water at the bottom of a fuel tank, i.e. b) the inverted cone system. Fig. S12 presents the de-water process of the inverted cone system in hexane. The small drops were sinking along the slope of the funnel and converge spontaneously, and slight shakes from the engine and movements of automobiles would also aid the water gathering process. Table 1 shows the water collection efficiency of the two systems, both systems have a water collection rate over $96 \%$. Compared with filtration methods (i.e., super-hydrophobic/oleophilic mesh, fabric, membrane, etc.), it is more efficient to collect small amount of water from large oil tank. 


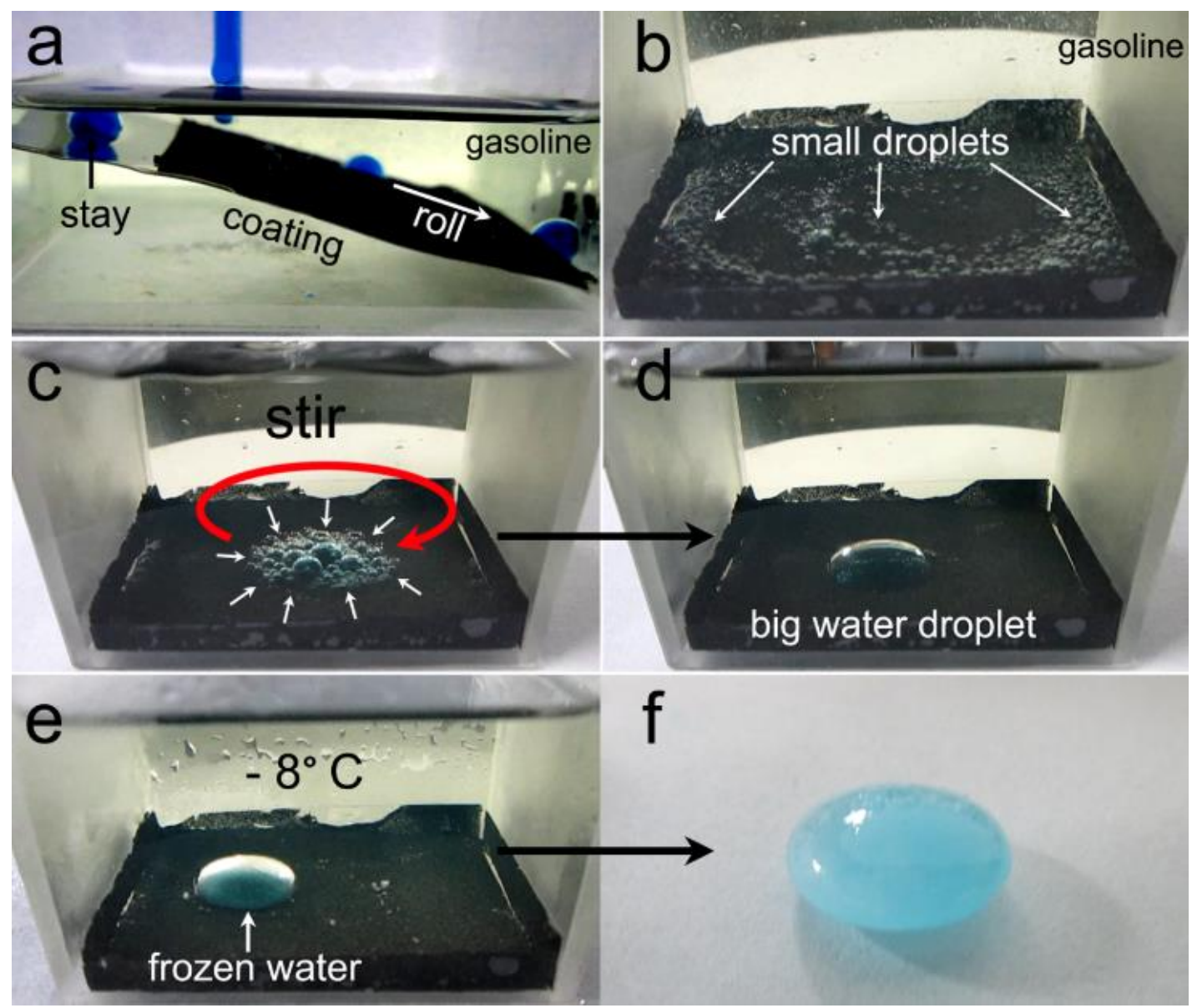

Figure 6. Super water repellency under oil and the stirring system for oil purification. (a)

Water droplets were repelled by the treated surface in oil. (b-f) Oil purification through stirring system. Small water droplets (diameter: $0.5 \sim 1 \mathrm{~mm}$ ) were added onto the treated surface, then mild stirring was applied. The separated small droplets rolled easily on the treated surface; they gathered together, combined, and eventually grown into a large water droplet in $\mathbf{d}$. The droplet froze under $-8^{\circ} \mathrm{C}$ and was taken out in $\mathbf{f}$.

Table 1. Water collection efficiency in hexane, gasoline and kerosene (\%)

\begin{tabular}{|c|c|c|c|}
\hline Methods & Hexane & Gasoline & Kerosene \\
\hline Stirring system & $99.0 \pm 0.5$ & $97.0 \pm 0.5$ & $99.5 \pm 0.4$ \\
\hline $\begin{array}{l}\text { Inverted cone } \\
\text { system }\end{array}$ & $99.5 \pm 0.4$ & $99.5 \pm 0.4$ & $99.5 \pm 0.4$ \\
\hline
\end{tabular}




\section{Conclusions}

We have developed a UHMWPE composite suspension to form a mechanically durable superhydrophobic coating on hard substrates that can resist long distance abrasion with low wear loss, blade scratching, tape-peeling, humidity, UV irradiation, as well as multiple-cycles of alternating high/low temperatures. This coating could be widely treated on various materials in any size and shape and the coating showed flexibility against 100 times bending and even folding into a tube, which could greatly increase its application. Furthermore, the nanomaterials used in the coating could be recycled and reconstructed without losing its superhydrophobicity. We also developed a perspective for the oil/water separation: using the movability of water on superhydrophobic surface to collect water from oil. This coating not only showed superior mechanical stability, but also created a surface that was durable, deformable, recyclable, not substrate-limited.

\section{Supporting Information}

Additional figures, Movies, This material is available free of charge via the Internet at http://pubs. rsc.org.

\section{Acknowledgements}

This work has received financial support from the National Natural Science Foundation of China (NO. 51575278), Special fund for the transformation of scientific and technological achievements in Jiangsu Province (NO.BA2015054), and A project funding by the Priority Academic Program Development of Jiangsu Higher Education Institutions (PAPD). 


\section{References}

1. M. J. Kwak, M. S. Oh, Y. Yoo, J. B. You, J. Kim, S. J. Yu and S. G. Im, Chem. Mater., 2015, 27, 3441-3449.

2. K. Li, J. Ju, Z. Xue, J. Ma, L. Feng, S. Gao and L. Jiang, Nat. Commun., 2013, 4, 2276.

3. D. D. Nguyen, N.-H. Tai, S.-B. Lee and W.-S. Kuo, Energy Environ. Sci., 2012, 5, 7908-7912.

4. J. C. Bird, R. Dhiman, H.-M. Kwon and K. K. Varanasi, Nature, 2013, 503, 385-388.

5. N. Wang, D. Xiong, Y. Deng, Y. Shi and K. Wang, ACS Appl. Mater. Interfaces, 2015, 7, 6260-6272.

6. L. Boinovich, A. M. Emelyanenko, V. V. Korolev and A. S. Pashinin, Langmuir, 2014, 30, 1659-1668.

7. S. Guldin, P. Kohn, M. Stefik, J. Song, G. Divitini, F. Ecarla, C. Ducati, U. Wiesner and U. Steiner, Nano Lett., 2013, 13, 5329-5335.

8. S. S. Latthe, P. Sudhagar, C. Ravidhas, A. J. Christy, D. D. Kirubakaran, R. Venkatesh, A. Devadoss, C. Terashima, K. Nakata and A. Fujishima, CrystEngComm., 2015, 17, 2624-2628.

9. S. T. Yohe, Y. L. Colson and M. W. Grinstaff, J. Am. Chem. Soc., 2012, 134, 2016-2019.

10. S. T. Yohe, J. A. Kopechek, T. M. Porter, Y. L. Colson and M. W. Grinstaff, Adv. Healthcare Mater., 2013, 2, 1204-1208.

11. S. Srinivasan, J. A. Kleingartner, J. B. Gilbert, R. E. Cohen, A. J. Milne and G. H. McKinley, Phys. Rev. Lett., 2015, 114, 014501.

12. B. Bhushan and Y. C. Jung, Prog. Mater. Sci., 2011, 56, 1-108.

13. D. Song, R. J. Daniello and J. P. Rothstein, Exp. Fluids, 2014, 55, 1-8.

14. W. Barthlott and C. Neinhuis, Planta, 1997, 202, 1-8.

15. K. Koch and W. Barthlott, Philos. T. R. Soc. A, 2009, 367, 1487-1509.

16. W. Barthlott, T. Schimmel, S. Wiersch, K. Koch, M. Brede, M. Barczewski, S. Walheim, A. Weis, A. Kaltenmaier and A. Leder, Adv. Mater., 2010, 22, 2325-2328.

17. Y. Cai, Q. Lu, X. Guo, S. Wang, J. Qiao and L. Jiang, Adv. Mater., 2015, 27, 4162-4168.

18. J.-S. Koh, E. Yang, G.-P. Jung, S.-P. Jung, J. H. Son, S.-I. Lee, P. G. Jablonski, R. J. Wood, H.-Y. Kim and K.-J. Cho, Science, 2015, 349, 517-521.

19. D. L. Hu, B. Chan and J. W. Bush, Nature, 2003, 424, 663-666.

20. K. Jin, J. C. Cremaldi, J. S. Erickson, Y. Tian, J. N. Israelachvili and N. S. Pesika, Adv. Funct. Mater., 2014, 24, 573-573.

21. C. Dorrer and J. r. Rühe, Langmuir, 2008, 24, 6154-6158.

22. G. D. Bixler and B. Bhushan, Nanoscale, 2014, 6, 76-96.

23. K. Ellinas, M. Chatzipetrou, I. Zergioti, A. Tserepi and E. Gogolides, Adv. Mater., 2015, 27, 2231-2235.

24. M. Im, H. Im, J.-H. Lee, J.-B. Yoon and Y.-K. Choi, Soft Matter, 2010, 6, 1401-1404.

25. Y. Lu, S. Sathasivam, J. Song, C. R. Crick, C. J. Carmalt and I. P. Parkin, Science, 2015, 347, 1132-1135.

26. S. Wang, K. Liu, X. Yao and L. Jiang, Chem. Rev., 2015, 115, 8230-8293.

27. F. Xue, D. Jia, Y. Li and X. Jing, J. Mater. Chem. A, 2015, 3, 13856-13863.

28. S. Hoshian, V. Jokinen, V. Somerkivi, A. R. Lokanathan and S. Franssila, ACS Appl. Mater. Interfaces, 2014, 7, 941-949. 
29. J. Ou, W. Hu, M. Xue, F. Wang and W. Li, ACS Appl. Mater. Interfaces, 2013, 5, 3101-3107.

30. Y. Wang, Y. Shi, L. Pan, M. Yang, L. Peng, S. Zong, Y. Shi and G. Yu, Nano Lett., 2014, 14, 4803-4809.

31. A. Checco, A. Rahman and C. T. Black, Adv. Mater., 2014, 26, 886-891.

32. B. Li and J. Zhang, Chem Commun., 2016, DOI: 10.1039/c5cc09951j.

33. B. Li and J. Zhang, Carbon, 2015, 93, 648-658.

34. K. Liu, M. Cao, A. Fujishima and L. Jiang, Chem. Rev., 2014, 114, 10044-10094.

35. L. Wu, L. Li, B. Li, J. Zhang and A. Wang, ACS Appl. Mater. Interfaces, 2015, 7, 4936-4946.

36. H. Zhou, H. Wang, H. Niu, A. Gestos, X. Wang and T. Lin, Adv. Mater, 2012, 24, 2409-2412.

37. V. H. Pham and J. H. Dickerson, ACS Appl. Mater. Interfaces, 2014, 6, 14181-14188.

38. J. Zhang, B. Li, L. Wu and A. Wang, Chem. Commun., 2013, 49, 11509-11511.

39. J. Huang, S. Li, M. Ge, L. Wang, T. Xing, G. Chen, X. Liu, S. Al-Deyab, K. Zhang and T. Chen, J. Mater. Chem. A, 2015, 3, 2825-2832.

40. S. Li, J. Huang, M. Ge, C. Cao, S. Deng, S. Zhang, G. Chen, K. Zhang, S. S. Al - Deyab and Y. Lai, Adv. Materials Interfaces, 2015, 2, 1570068.

41. S. S. Latthe, P. Sudhagar, A. Devadoss, A. M. Kumar, S. Liu, C. Terashima, K. Nakata and A. Fujishima, J. Mater. Chem. A, 2015, 3, 14263-14271.

42. F. Su and K. Yao, ACS Appl. Mater. Interfaces, 2014, 6, 8762-8770.

43. J. Chen, R. Dou, D. Cui, Q. Zhang, Y. Zhang, F. Xu, X. Zhou, J. Wang, Y. Song and L. Jiang, ACS Appl. Mater. Interfaces, 2013, 5, 4026-4030.

44. J. Zimmermann, F. A. Reifler, G. Fortunato, L.-C. Gerhardt and S. Seeger, Adv. Funct. Mater., 2008, 18, 3662-3669.

45. T. Darmanin and F. Guittard, J. Am. Chem. Soc., 2011, 133, 15627-15634.

46. R. Yuan, H. Wang, T. Ji, L. Mu, L. Chen, Y. Zhu and J. Zhu, J. Mater. Chem. A, 2015, 3, 19299-19303.

47. C. Douvris and O. V. Ozerov, Science, 2008, 321, 1188-1190.

48. L. Feng, Z. Zhang, Z. Mai, Y. Ma, B. Liu, L. Jiang and D. Zhu, Angew. Chem. Int. Ed., 2004, 43, 2012-2014.

49. C. H. Lee, N. Johnson, J. Drelich and Y. K. Yap, Carbon, 2011, 49, 669-676.

50. C. R. Crick, J. A. Gibbins and I. P. Parkin, J. Mater. Chem. A, 2013, 1, 5943-5948.

51. B. Wang, J. Li, G. Wang, W. Liang, Y. Zhang, L. Shi, Z. Guo and W. Liu, ACS Appl. Mater. Interfaces, 2013, 5, 1827-1839.

52. W. Zhang, Z. Shi, F. Zhang, X. Liu, J. Jin and L. Jiang, Adv. Mater., 2013, 25, 2071-2076.

53. M. Ohta, S.-H. Hyon and S. Tsutumi, Wear, 2003, 255, 1045-1050.

54. M. A. Samad, N. Satyanarayana and S. K. Sinha, Surf. Coat. Tech., 2010, 204, 1330-1338.

55. D. Silbernagl, H. Sturm and B. Cappella, Langmuir, 2009, 25, 5091-5097.

56. K. L. Mittal, Adhesion Aspects of Polymeric Coatings, Plenum Press, New York, 1981, ch. 1897, 20-21.

57. M. Minn and S. K. Sinha, Wear, 2010, 268, 1030-1036.

58. B. Panjwani, N. Satyanarayana and S. K. Sinha, J. Mech. Behav. Biomed., 2011, 4, 953-960.

59. M. A. Samad and S. K. Sinha, Tribol. Int., 2011, 44, 1932-1941.

60. D. Xiong, Mater. Lett., 2005, 59, 175-179.

61. M. K. Whittlesey and E. Peris, ACS Catal., 2014, 4, 3152-3159. 
62. T. L. Gianetti, R. G. Bergman and J. Arnold, Chem.Sci., 2014, 5, 2517-2524.

\section{Graphical Abstract}

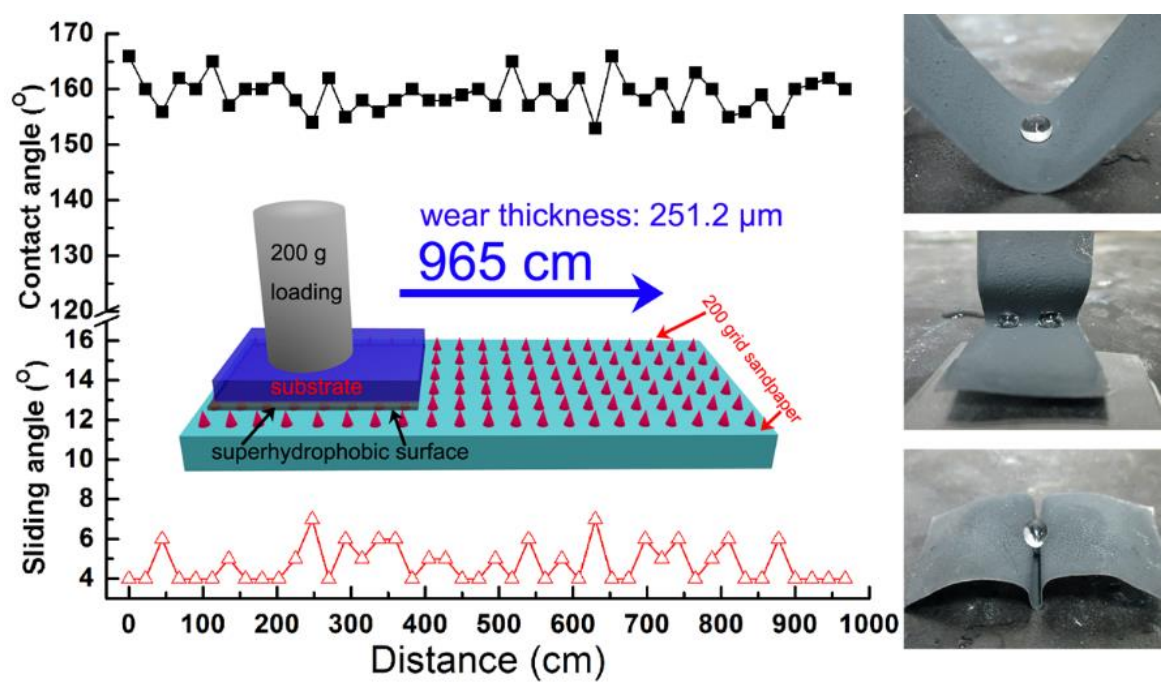

UHMWPE based superhydrophobic coating shows superior mechanical durability and flexibility. 